\title{
Design and Implementation of an Interactive System for Teaching the Islamic Prayer
}

\author{
Mohammed Farsi ${ }^{1}$, Malcolm Munro ${ }^{2}$ \\ ${ }^{1}$ School of Engineering and Computing Sciences, Durham University, England, UK \\ ${ }^{2}$ Collage of Computer Science and Engineering, Taibah University, Yanbu, Saudi Arabia \\ Correspondence: Mohammed Farsi, School of Engineering and Computing Sciences, Durham University, England, UK
}

Received: January 26, 2016 Accepted: February 14, $2016 \quad$ Online Published: March 22, 2016

doi:10.11114/jets.v4i5.1481 URL: http://dx.doi.org/10.11114/jets.v4i5.1481

\begin{abstract}
Background: The Islamic Prayer is central to the Islam religion and is a requirement for all Muslims to learn and perform properly. Teaching the Islamic Prayer had traditionally been through the use of textbooks.

Aims: This paper describes the design and implementation of the IIP (interactive Islamic Prayer) system to teach the Islamic prayer using Virtual Environments and interactive technologies.

Method: The approach taken was to first define the various elements that make up the Islamic Prayer (positions, verbal statements and units). This is then captured in software that uses the Microsoft Windows Kinect system.

Results: The Islamic Prayer sequences were successfully captured and implemented in the iIP system.

Conclusions: The iIP system design and implementation using Microsoft Windows Kinect system was described. This was based on the definition of the different elements of the Islamic Prayer.
\end{abstract}

Keywords: human-computer interaction, virtual environments, Islamic prayer, kinesthetical learning, x-box 360 kinect, learning preferences

\section{Introduction}

Virtual Environments and Interactive Technologies can be used to enhance the learning process (Rieber 1996). This paper describes the design and implementation of the interactive Islamic Prayer (iIP) system (Farsi 2015) that teaches the Islamic Prayer to school children in an interactive virtual environment.

The Islamic Prayer is a fundamental requirement for all Muslims to learn and perform properly. Teaching the Islamic Prayer had traditionally been through the use of textbooks. The majority of the Muslim population do not live in Muslim countries where the prayer is fully established and taught. This alone is a justification to support a new interactive system particularly as an educational tool or supplement. In developing software based interactive learning system the approach taken is to first define the various elements that make up the Islamic Prayer (positions, verbal statements and units), research a suitable virtual environment, and realise the system by using suitable tools.

One important aspect to take into consideration is that of the learning styles of the intended audience. Fleming et al (2001) defined four modalities of learning styles, Visual, Aural, Read/Write, and Kinesthetic. The model states that learners have a dominant learning style or preference which can provide greater depth of learning for them. These are broken down into the following styles:

- Visual preference: in the form of graphical or pictorial representations

- Aural preferences: in the form of listening to lectures or discussions

- Read/Write preferences: in the form of reading and writing texts and words

- Kinesthetic preferences: in the form of doing and use of action

The iIP system seeks to cater for all these styles through incorporating each style in its design. Analysis from the perspective of the traditional method of teaching it can be postulated that the development of a system like iIP is more appealing to learners as the lesson itself is not teacher-cantered nor does it cater for one style of teaching. Rather, the appeal is greater as it is envisaged that this approach will provide a greater learning experience and some sense of 
achievement for the learners. Experimental results showed that it was effective in addressing different styles of learning in school children. The viability of the IIP system when used by school children was evaluated through a series of experiments and is described by Farsi (2015) and Farsi and Munro (2016).

The iIP system is a learning tool that has been designed specifically for the Microsoft Windows Kinect so that learners can immerse themselves into the prayer through physical interaction without the need of a controller. This means that the learners can model their learning through the iIP system and actually perform the prayer movements in sequence that the system recognises and then assesses the learner's progress accordingly.

\section{The Islamic Prayer Process}

Within the design of the iIP Software, there are certain aspects of the actual prayer process that need to be addressed and defined. These include how the prayer is performed, the names for each prayer movement, what verbal statements are made during each position, the prayer times for each of the five main prayers and how many units each prayer consists of.

Each of the five daily Islamic prayers consists of a sequence of position that are performed by the user, each one is made up of a different number of units. Figure 2-1 shows each specific movement that is performed in one unit of prayer Piet (2011). The focus for the iIP Software is to ensure that users are performing the prayer positions correctly and in the correct order. The design takes into consideration how users should complete one unit of prayer using the interactive Software.

$$
\text { START }
$$

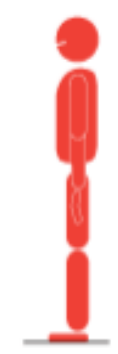

01

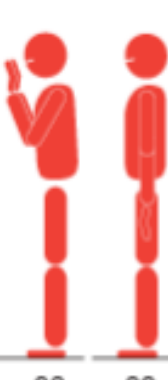

03

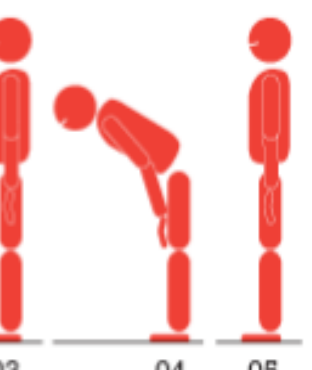

$04 \quad 05$
ONE RAKA'AH (ONE ROUND)

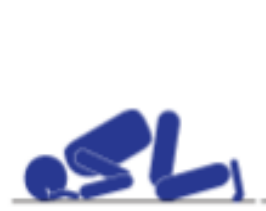

06

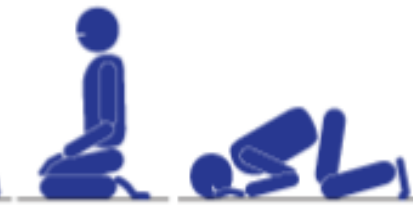

08

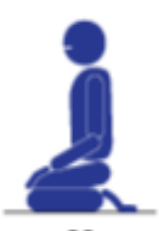

09 FINISH

Figure 2-1.The Islamic prayer postions and levels

In addition, the verbal statements that are made during each prayer position are Arabic phrases that have been predefined within Islamic teachings. Table 2-1 shows the list of all the verbal statements that are made at different position of the prayer. For the purpose of the iIP design, each verbal statement has been assigned a statement code, which is used to identify when it should be made.

Table 2-1. A transliteration of the Arabic statements used during the prayer postions

\begin{tabular}{cl}
\hline Statement Code & verbal Statement \\
\hline S1 & "Allahu Akbar." \\
S2 & "Surat ul Fatihah" + "any Surat " \\
S3 & "Subhana Rabbiyal Adhim." \\
S4 & "Sami'Allahu liman hamidah" + "Rabbana wlaka alhamd." \\
S5 & "Subhana Rabbiyal A'la." \\
S6 & "Rabbighfir li." \\
& "Assalamu alaikum wa rahmatullah" \\
T1 & As-Tahiyyatu lillahi was- Salawatu wat-Tayyibatu. \\
& Assalamu 'alaina wa'ala ibadil-Lahis -Salihin ash hadu al-La ilaha il-Lal lahu \\
& wa ash hadu anna Muhammadan abduhu wa rasuluhu." \\
& "Allahumma salli 'ala Muhammadin Wa 'ala ali Muhammadin \\
T2 & Kama sallaita 'ala Ibrahima wa 'ala ali Ibrahima \\
& wa barik 'ala Muhammadin wa 'ala ali Muhammadin \\
& Kama barakta ' ala Ibrahima Wa ' ala ali Ibrahima \\
& Fil a'lamina Innaka hamidun Majid." \\
\hline
\end{tabular}

From the list of statements that will be uttered within the prayer, Table 2-2 shows the actual correlation between the position and the verbal statements by illustrating the prayer position name, a visual representation of the position and which verbal statement is uttered at that particular time (using the statement code from Table 2-1). 
Table 2-2. Statement codes assigned to their prayer psotion

Level

01

02

04

05

06

07

08

09

10

\section{Prayer Position name}

Visual image of the prayer position

Qiyaam (stand upright facing the dircation of

ALKa'bah )

Takbeer Al-ihraam (Entering the prayer)

Place your right hand on top of your left hand

Stand up from the bowing position

Sujood (prostration)

Al-Jaloos (sitting )

Sujood position

Al-Jaloos (sitting ), Tashahhud

Tasleem (closing the prayer)
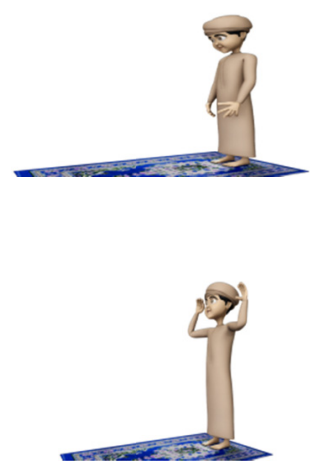

S1

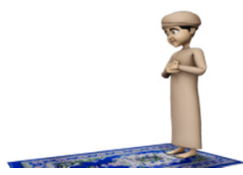

S2, S1

S3

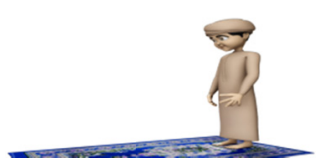

S4, S1

S5 , S1

S6, S1

S5, S1

T1,T2

S7 
Each prayer consist of a number of units (Arabic: Rak'ah). Within each prayer, there are three types of Rak'ah that correspond to the prayer position that are shown in Figure 2-1. These types of Rrak'ah are represented using a code in Table 2-3. For instance, Rak'ah \#1 indicates the user will perform the sequential movements from level 1-8.

Table 2-3. The Rak'ah in relation to the prayer positions level

\begin{tabular}{lcr}
\hline & Units (Arabic: Rak'ah) Types & Code \\
\hline $\mathbf{1}$ & Rak'ah \#1 (Level 1-8) \\
& \\
& Rak'ah \#2 (Level 1-9) & $\mathbb{E}$ \\
3 & & $\mathbb{N}$ \\
& &
\end{tabular}

In each of the five daily prayers, the time of day and the number of Rak'ah for each prayer differs. Table 2-4 shows the prayer names in Arabic and the time period when each prayer is to be performed. Furthermore, the code that has been defined in Table 2-3 is also used to describe the number of Rak'ah in each of these prayers.

Table 2-4. Prayer names with their times and units

\begin{tabular}{l|cc}
\hline \multicolumn{2}{c}{ Prayer Name } & Prayer times \\
Fajr & One hour before Sunrise - Sunrise & Units (Rak'ah) \\
Zuhr & Noon - Evening & $\square$ \\
Aser & Evening - Sunset & $\square$ \\
Magreb & Sunset - Night & $\mathbb{N}$ \\
Isha & Night - (One hour before Sunrise) & $\mathbb{N}$
\end{tabular}

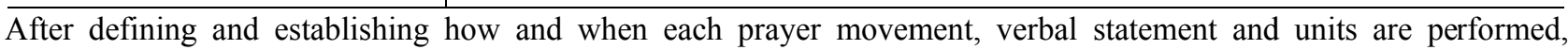
Figures 2-2 provide a specific breakdown of the Zuhr prayer.

The Zuhr prayer begins with Rak'ah \#1 (Table 2-3), which corresponds to the position levels1-8 (Figure 2-1). In each position, certain verbal statements are made that correspond to the statement codes in Table 2-1. Upon completing position 8, the user then goes to Rak'ah \#2 (Table 2-3) and performs position levels 1-9 (Figure 2-1) with the assigned verbal statements. Upon completion of position 9, the user makes the statements T1 and S1 (Table 2-1), and then goes to Rak'ah \#1 (Table 2-3) and performs it as before. Lastly, the user completes Rak'ah \#3 (Table 2-3), where they complete all the positions from levels 1-10 (Figure 2-1). The final position (and statement code S7) is used to end the prayer. It should be noted that each Rak'ah refers to the prayer in an ordinal sequence, which means the Zuhr prayer is made up of 4 units. 


\section{Zuhr Prayer (noon or Afternoon)}

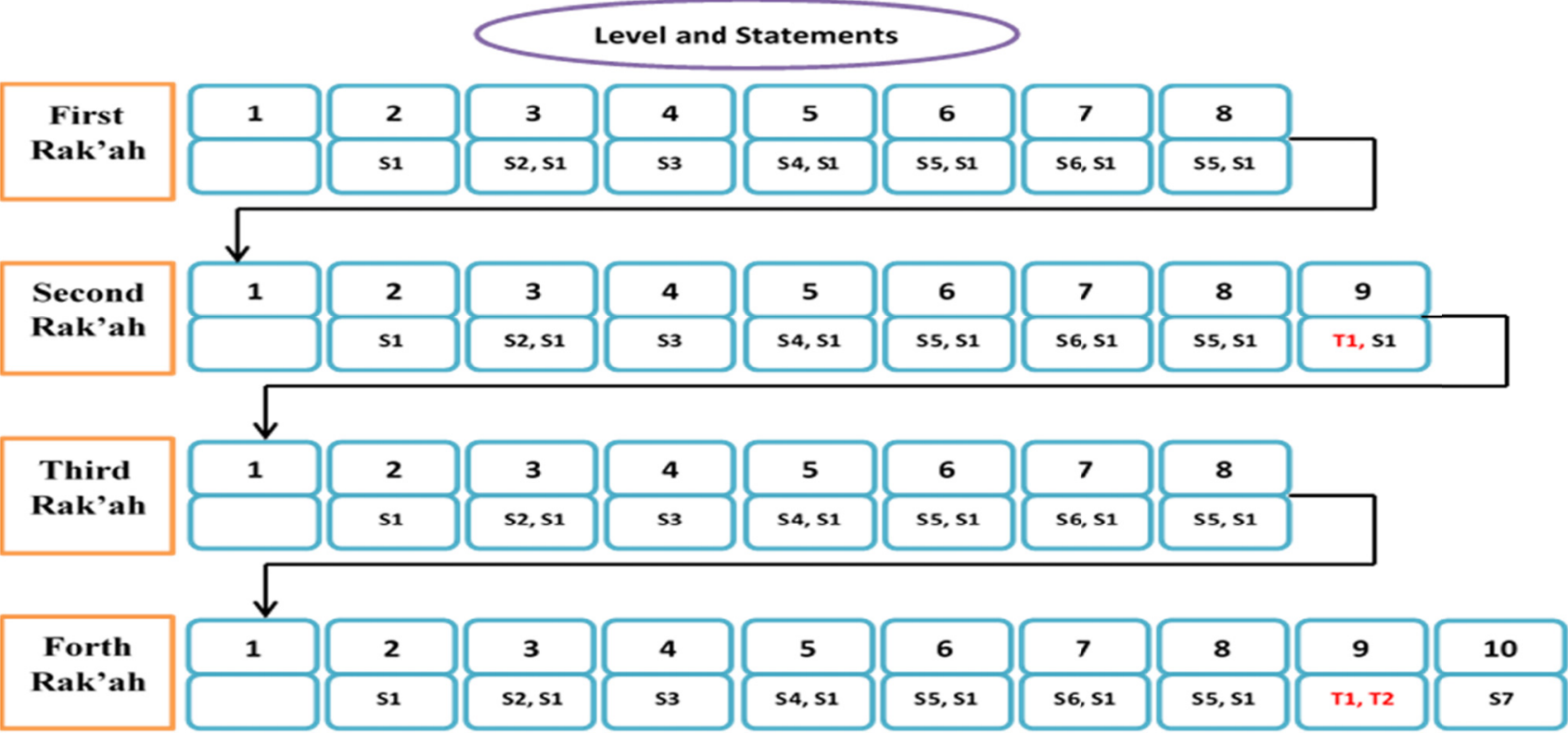

Figure 2-2. Sequence of positions and units for the Zuhr Prayer

\section{Design and Implementation of the iIP Software}

Upon opting for the Microsoft Windows Kinect as the desired console, it was identified that specific phases would be incorporated in order to construct the iIP Software. Figure 3-1 illustrates the phases of the implementation. Moreover, it should be noted that during each phase, a number of development tools were used, such as graphic editing Software to design the Start Screens and GUI; 3D modeling Software to create the instructional coach avatar; programming editing Software to develop the code that was necessary for the Microsoft Kinect. What follows is a detailed insight into each phase and the tools that were used. 


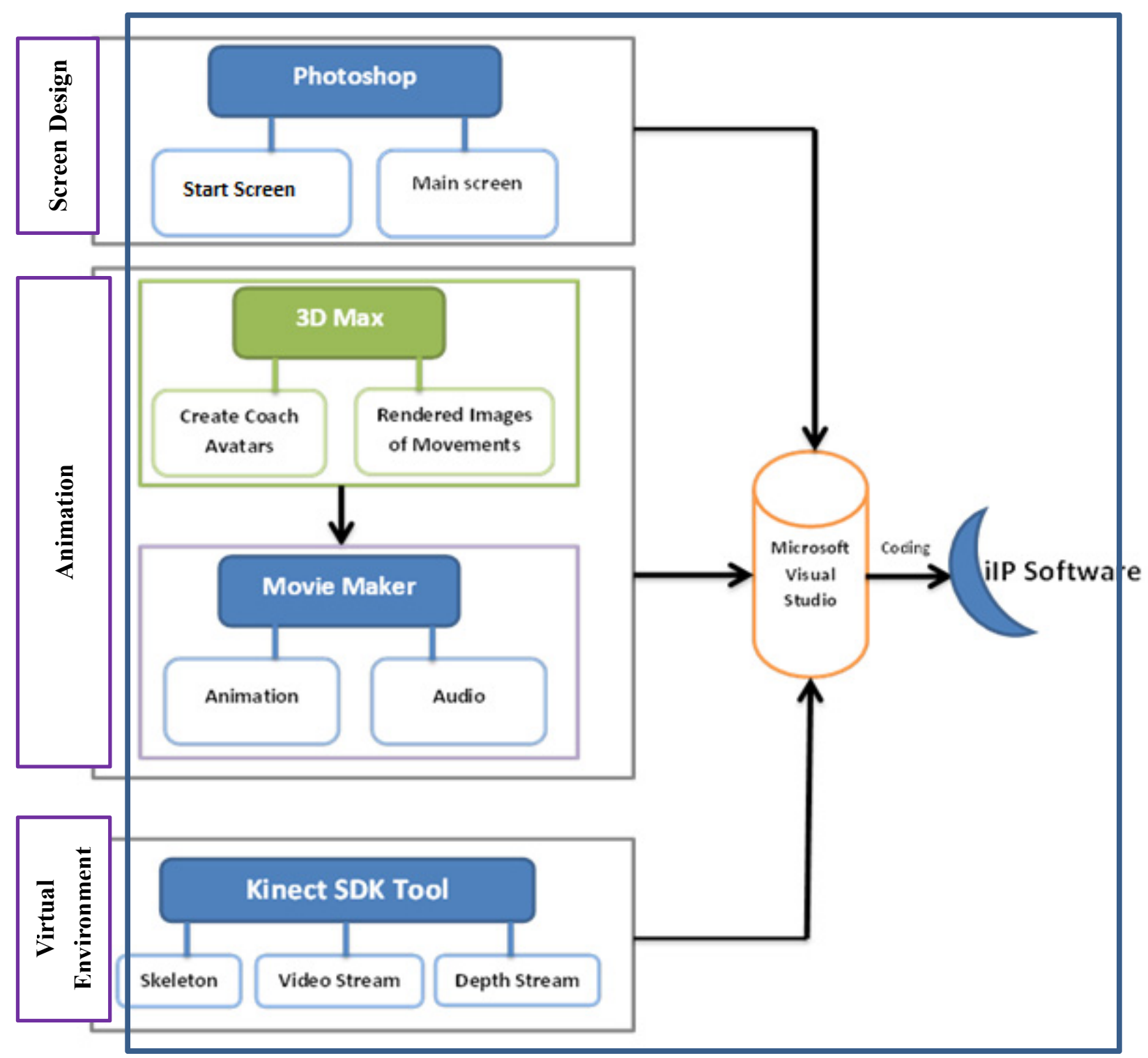

Figure 3-1. Phase of implementation for the iIP Software

\subsection{Screen Design}

The initial phase was to design the various interface screens, graphics and logos that would be used in the iIP Software. Adobe Photoshop CS 8.0 was primarily used in this regard, which is a common image-editing program used by graphic designers to edit and enhance digital pictures and graphics (Figure 3-2). When designing the background screens, a particular colour scheme (i.e. light colours) was used throughout so it would not strain the users' vision and make it easy to follow what else was on the screen. 


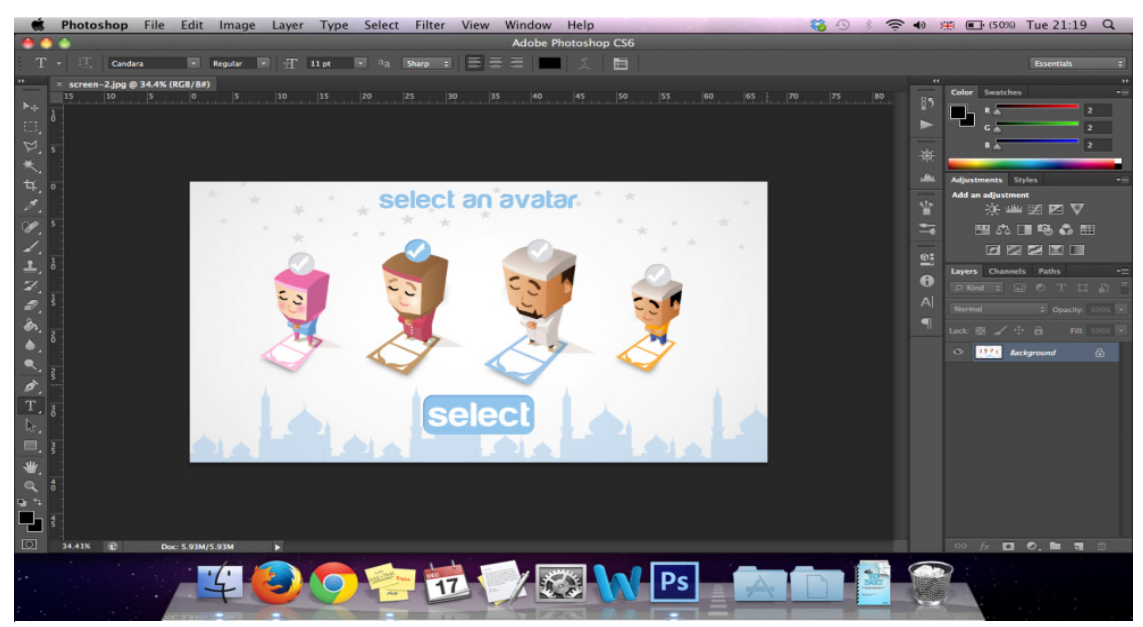

Figure 3-2: Adobe Photoshop CS 8.0

\subsection{Animation}

Autodesk 3DS Max Design 2013 was used to generate 3D models of the instructional coach avatars (Figure 3-3). As 3D computer graphic Software, 3DS Max is frequently used in games as well as special effects in TV and movies. Four models were designed for different genders and ages. Each position of the prayer is developed by creating an array of still images of the position from beginning to end.

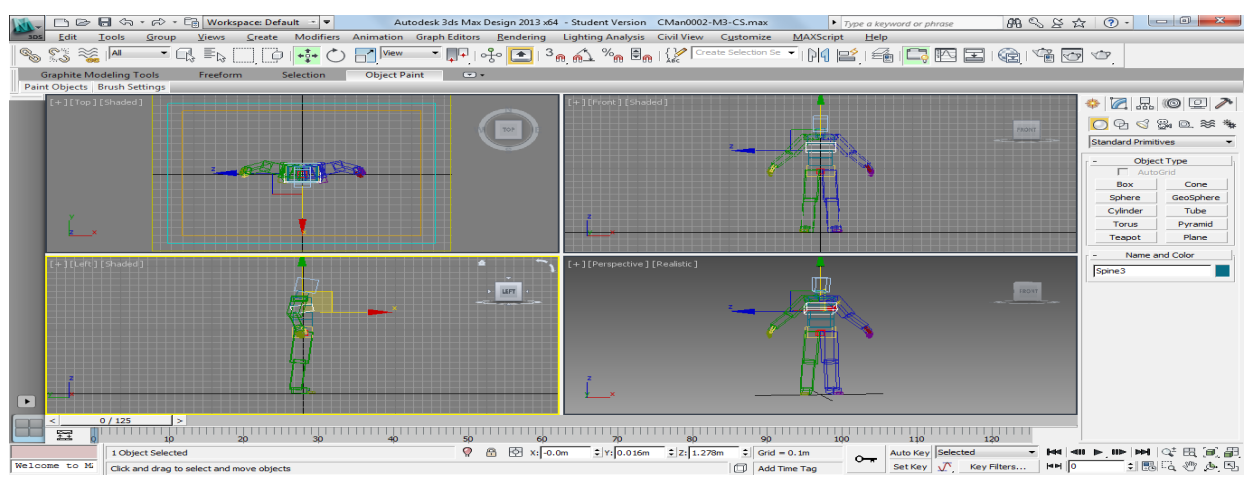

Figure 3-3. Autodesk 3DS Max Design 2013

In order to animate the 3D avatars, a basic video-editing program that can be used to insert the still images of the $3 \mathrm{D}$ generated models in the correct order was required. As a result, Microsoft Movie Maker was used, and once the still images of all the movements were added, it was split into each specific prayer position and movement (Figure 3-4).

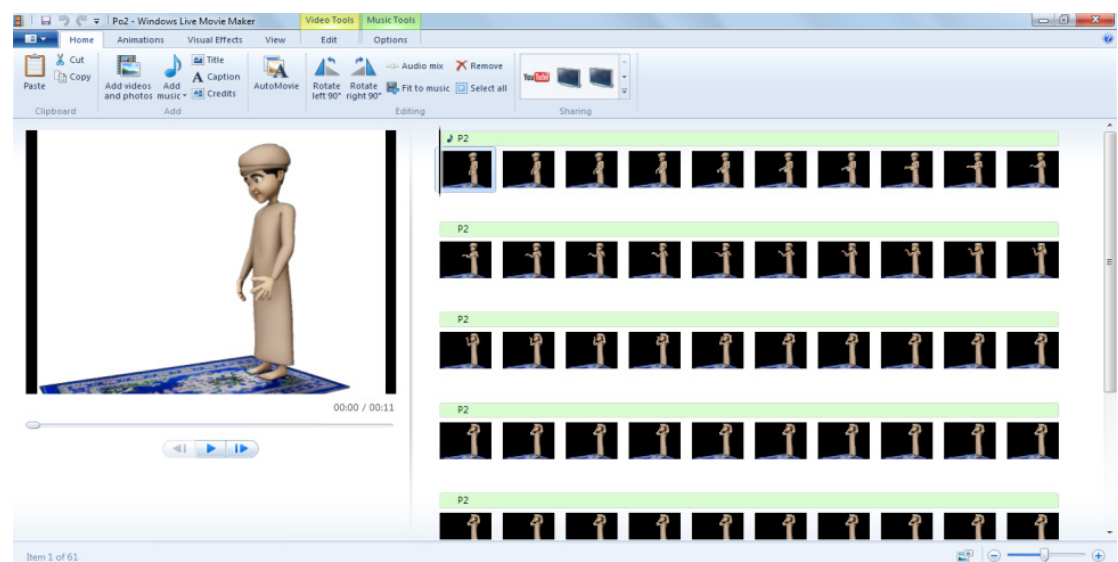

Figure 3-4. Microsoft Movie Maker design 


\subsection{Virtual Environment}

The next phase was to initiate the core component of the iIP Software, which was the actual coding for it to run effectively on the Xbox 360 Kinect. For this phase, two main development tools were utilized: Microsoft Visual Studio 2010 (using Microsoft XNA tools) and the Microsoft Kinect for Windows Software Development Kit (SDK) version 1.7. The SDK toolkit comprises of a vast reference library that is used to incorporate into Visual Studio for XBox Kinect application development (Figure 3-5).

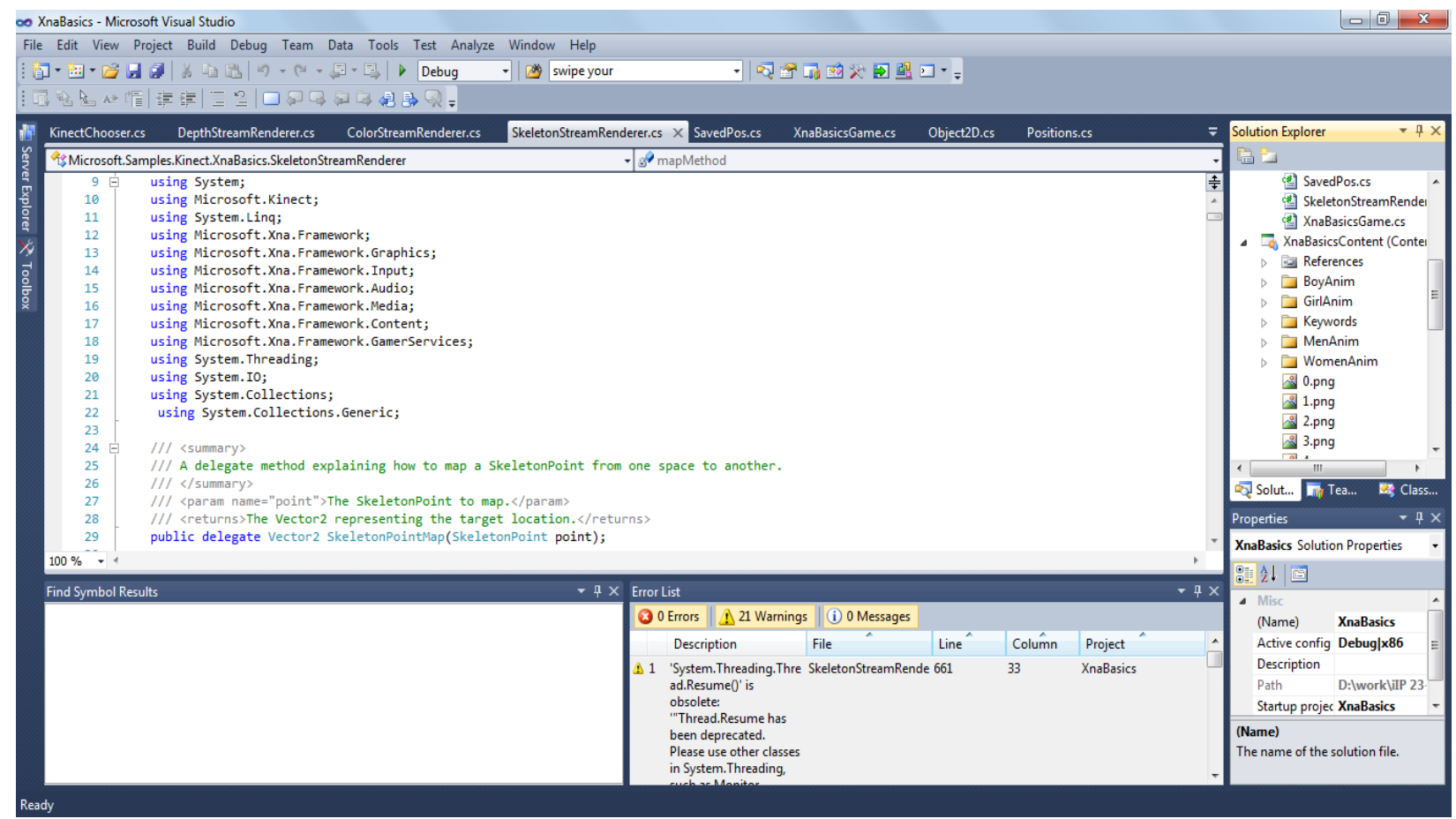

Figure 3-5. Microsoft Visual Studio (Coding Phase)

For the iIP Software, three of the SDK elements (Skelton, Video Stream, Depth Video) were used, which were related to the skeleton tracking and hand pointer, depth and video stream camera. The output of the previous phases (Screen Design and Animation) were incorporated into Visual Studio 2010 as this was the main program used for final coding and implementation. During this phase, a structure and process for how the coding would be implemented was drawn up in a flow chart diagram (Figure 3-7).

As part of the coding, the iIP Software uses a comparison algorithm when determining whether the user has performed each prayer movement correctly, by analysing the human motion across the $\mathrm{X}$ and $\mathrm{Y}$ axis of the depth camera. To achieve this, each prayer movement was captured using Visual Studio, whereby the actual human motion was recorded and titled accordingly (i.e. Level 1, Level 2 etc). Following this, an algorithm in C\# that compares the X and Y coordinates of real-time and saved movements were tested, the flexibility is show by the + or - radius (value 120) within the coordinates to take into account slight variations of each user (Figure 3-6). 


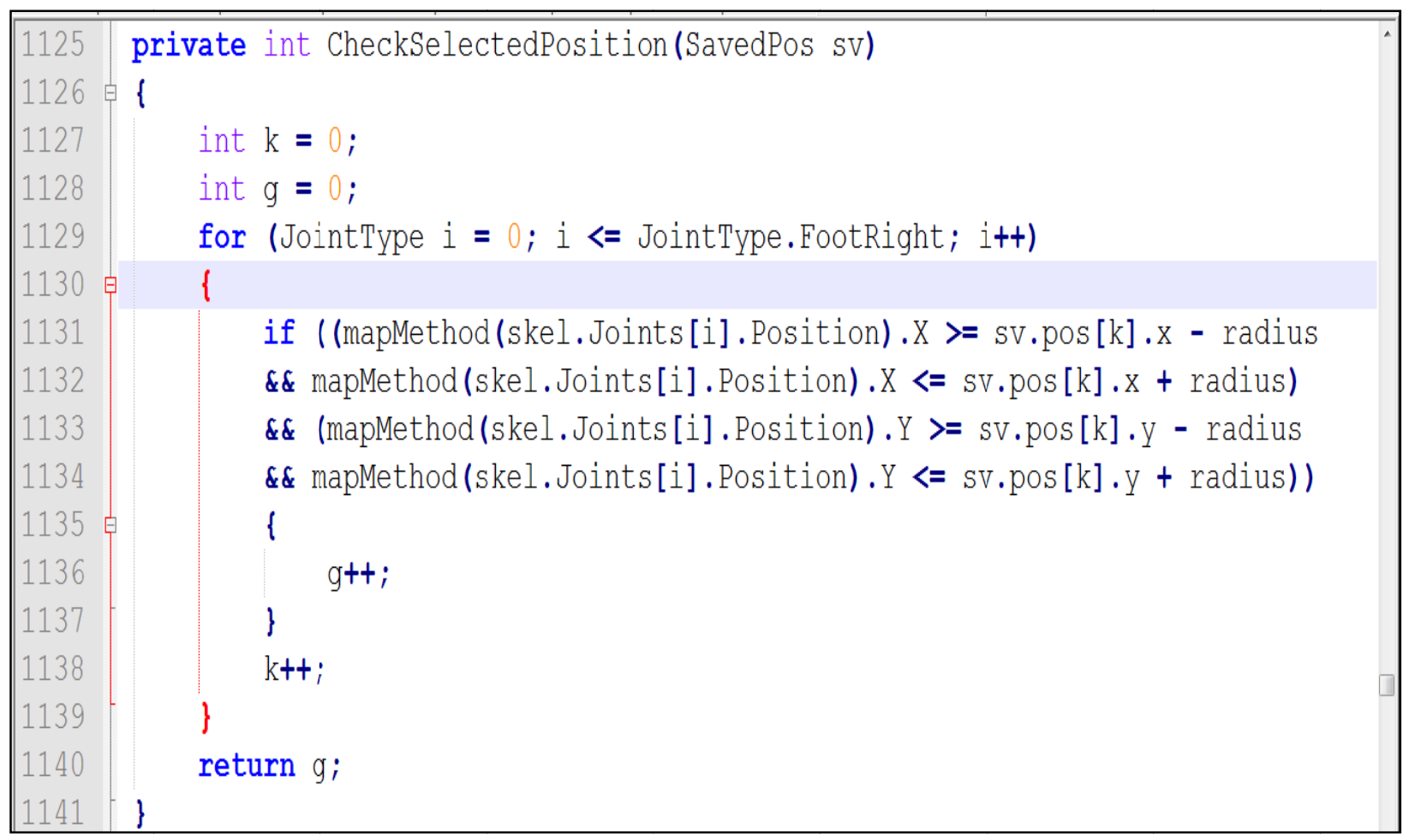

Figure 3-6. C\# code for the skeleton position algorithm in comparison to saved position

In addition, the coding also incorporated various checks and balances to establish whether the user was in the correct position before proceeding to the actual prayer (Figure 3-7). This is important within the context of the Islamic prayer because the prayer begins in the standing position.

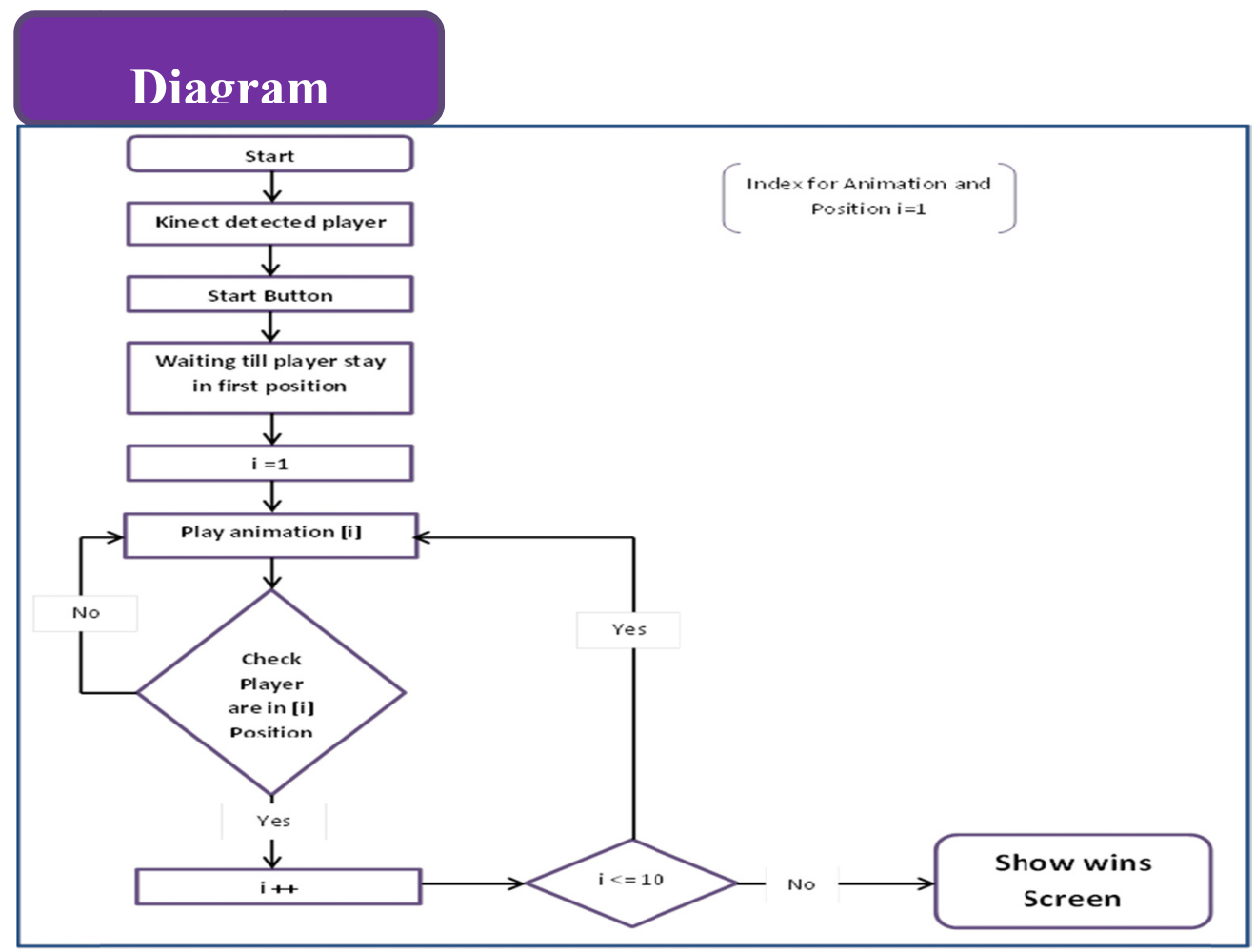

Figure 3-7. A process flow-chart for iIP Software 


\section{Conclusion}

This paper has defined the Islamic Prayer process and described the design and implementation of the iIP (interactive Islamic Prayer) system. Defining the Islamic Prayer process is an important step in designing a teaching system. The iIP system provides a virtual environment for teaching the Islamic Prayer. An important aspect of the design of iIP is that it incorporates different learning styles.

\section{Acknowledgement}

I would like to express my gratitude to Taibah University in Saudi Arabia for sponsoring my scholarship for this research.

\section{References}

Farsi, M. (2015). Interactive Islamic Prayer. PhD thesis Durham University, Durham, England.

Farsi, M., \& Munro, M. (2016). A Comparative Study of Teaching the Islamic Prayer, International Journal of Information and Education Technology (IJIET), ISSN: 2010-3689 6(5).

Fleming, N., Dunn, J., \& Bonwell, C. (2001). VARK a Guide to Learning Styles, retrieved from http://www.vark-learn.com/english/index.asp (access on September 2013)

Piet, M. (2011). The Last Hour, retrieved from https://markpiet.wordpress.com (access on September 2013)

Rieber, L. P. (1996). Seriously considering play: Designing interactive learning environments based on the blending of microworlds, simulations, and games. Educational Technology Research and Development.

\section{$(\mathrm{cc}) \mathrm{BY}$}

This work is licensed under a Creative Commons Attribution 3.0 License. 